\title{
TEATRO NA SÃO FRANCISCO. UM MERGULHO NA HISTÓRIA
}

\author{
THEATRE IN THE “SÃO FRANCISCO”. A HISTORIC DIVING
}

Maria da Conceição Vitor*

\begin{abstract}
Resumo:
A proposta do presente artigo é resgatar um pouco da história do teatro estudantil, com ênfase no centenário grupo formado pelos estudantes da Faculdade de Direito do Largo de São Francisco, no início de 1829. A memória de um povo ou de uma instituição é a sua identidade, a referência e a prova de sua passagem pela raça que representa, e pela própria história do planeta. Em que pese a personalidade romântica que lhe é atribuída, o brasileiro ainda não tem o hábito da preservação da memória histórica de sua própria existência, desde guardar uma foto ou um fato da infância até guardar e resguardar a história do próprio país, dilapidando suas memórias, seus monumentos, seus recursos naturais, seus patrimônios culturais e os personagens desse grande teatro que é a vida.
\end{abstract}

Palavras-chave: Teatro. História. Memória. Patrimônio. Cultura. Estudantes. Faculdade de Direito, Largo de São Francisco.

\begin{abstract}
:
The purpose of this article is to rescue a little bit of the history of student theatre, with emphasis in the centenary team formed by the Largo de Sao Francisco Law School students, in the beginning of the year 1829. The memory of a people of an institution is its identity, the reference and the evidence of its passage by the race that represents, and by the own history of planet. Despite of the romantic personality assigned to Brazilian people, he do not have the habit of preservation of historic heritage of its own existence, since keeping a photo or a fact from its infancy, to keep and preserve the history of his country, dilapidating his memories, its monuments, its natural resources, his cultural heritages and personages of this big theatre: the life.
\end{abstract}

Keywords: Theater. History. Memory. Patrimony. Culture. Students. Law school, Plaza of San Francisco

Um pouco de história

Ao mergulharmos fundo na história humana podemos perceber que a origem do teatro remonta desde as primeiras sociedades primitivas, quando se acreditava no poder sobrenatural da dança imitativa como controladora dos fatores essenciais à sobrevivência, tais como a fertilidade da terra, a moradia, o sucesso nas batalhas, etc.; acrescentandose, ainda, o caráter de exorcização dos maus espíritos. Evidencia-se, portanto, o caráter ritualístico. Com o conhecimento do homem no que se refere aos fenômenos naturais,

\footnotetext{
Bacharel em Comunicação Social - Jornalismo. Redatora e editora do Jornal "O São Francisco". ChefeSubstituta do Serviço Técnico de Imprensa da Faculdade de Direito da Universidade de São Paulo.
} 
as características ritualísticas do teatro vão sendo substituídas pelas características mais voltadas à educação, com a representação de lendas relacionadas aos deuses e heróis.

Historicamente, o teatro teve sua origem na Grécia, por volta do século IV a.C., nas chamadas festas dionisíacas, em homenagem ao deus Dionísio (Baco, para os latinos) que era o deus do vinho, do teatro e da fertilidade. Consistiam em rituais sagrados, procissões e recitais que aconteciam a cada primavera, período da colheita da uva na região.

Um acontecimento inusitado foi o marco inicial da ação dramática no mundo. Conta-se que um participante de um desses rituais resolveu usar uma máscara humana, ornada com cachos de uvas, e subiu a um tablado em praça pública, dizendo: "Eu sou Dionísio!". A coragem do moço em fingir-se um deus espantou a todos. Chamava-se Téspis e é considerado o primeiro ator da história do teatro ocidental. Ele ousou "transformar o sagrado em profano, a verdade em faz-de-conta, o ritual em teatro, e pela primeira vez, diante de outros, mostrou que poderíamos representar o outro”. (infoescola/2008).

Surgem, na Grécia, a tragédia e a comédia introduzidas por Ésquilo e Sófocles, e também a peça satírica de Aristófanes, mesclando a paródia mitológica com a sátira política. Detalhe: não era permitida a participação de mulheres. Concomitantemente, surgem as primeiras construções teatrais, constituídas basicamente da seguinte estrutura: arquibancada, orquestra, thumelê, proscênio e palco.

O teatro grego era construído ao ar livre, aproveitando as encostas de montanhas e colinas de pedra como suporte para o escalonamento das arquibancadas, dispostas de tal forma que cada pessoa podia assistir as representações com a mesma qualidade de visão. Curiosamente, com os parcos recursos da época, a acústica era perfeita, tanto que quem estivesse na última fileira tinha a mesma percepção da voz do ator de quem estava na primeira fileira.

A orquestra era o espaço central circular, onde se apresentava o coro, que era formado por dançarinos. Uma pedra fincada no centro da orquestra e que se destinava às oferendas do deus Dionísio era a thumelê. $\mathrm{O}$ proscênio, espaço entre a orquestra e o palco, era o local onde ficava o corifeu, líder do coro. O palco, inicialmente construído de madeira e posteriormente em pedra, era o espaço destinado aos cenários e à troca de figurinos e máscaras.

Chegamos a Roma: um teatro fortemente influenciado pelo teatro grego, cujos baluartes foram Plauto e Terêncio. O detalhe é que, até 55 a.C., não possuíam um local fixo para as apresentações, as quais eram realizadas em grandes tendas, com capacidade para abrigarem cerca de 40 mil espectadores. Com o advento do Cristianismo, o teatro passou a ser considerado pagão e perdeu o apoio dos patrocinadores, o que culminou com a completa extinção das atividades teatrais. Paradoxalmente, foi por intermédio da própria Igreja, na Era Medieval, que renasceu o teatro, agora utilizado como veículo propagador 
de conteúdos bíblicos e tendo como atores os próprios padres e monges. Essa modalidade teatral medieval-religiosa conheceu seu declínio a partir de meados do século XVI.

A essa época, já surgira na Europa o chamado teatro elisabetano (século XV), no qual os atores, ainda exclusivamente homens, eram empregados pela nobreza e pela realeza, a exemplo de William Shakespeare, que era empregado do Lorde Chamberlain.

A Itália ainda foi palco do teatro renascentista, rompendo com as tradições do teatro medieval e inaugurando as representações do chamado teatro humanista. Surgiu com a "Commedia Dell'Arte" um intenso processo de profissionalização do ator e a utilização de mulheres nas representações; este último, o traço mais marcante que se estendeu em toda a Europa, principalmente Inglaterra e França.

A partir do século XVIII, as mudanças estruturais da dramaturgia foram reflexos de acontecimentos históricos como a Revolução Industrial e a Revolução Francesa. Surgiram, nessa época, o melodrama, bem ao gosto da grande massa, e uma série de inovações técnicas. Com a descoberta da luz a gás (século XIX), os recursos de iluminação deram uma nova perspectiva ao teatro e o primeiro a usar o recurso da luz elétrica, em 1881, foi o Savoy Theater, de Londres. Os cenários e figurinos passaram a reproduzir mais realismo, e as sessões teatrais, antes com várias peças, apresentavam, agora, uma única encenação. Essa verdadeira metamorfose pela qual passou a dramaturgia fez surgir a figura do diretor, administrador de todos os estágios artísticos de produção.

Em fins do século XIX, alguns autores começaram a assumir uma tendência bem diversa de seus românticos antecessores, fazendo da arte de representar um veículo de denúncia da realidade vista de um ângulo particularista, entre eles Henrik Ibsen (Noruega: 1828-1906) com o seu "teatro de idéias", e Emile Zola (França: 1840-1902) introdutor da corrente naturalista.

A partir do século $\mathrm{XX}$, o teatro quebrou todas as correntes tradicionais para cair no ecletismo de conteúdo, estilo de interpretação, direção, infra-estrutura, design cênico, longe de padrões predominantes. No teatro contemporâneo, tanto as tradições realistas quanto as não-realistas convivem simultaneamente.

Finalmente o Brasil. Aqui o teatro teve origem com as representações para catequização dos índios, protagonizadas pelos monges da Companhia de Jesus, nos idos de 1550, cujos principais autores foram os padres José de Anchieta e Antonio Vieira. Eram peças didáticas, visando introduzir a crença cristã na cultura indígena.

Os jesuítas recebiam ensinamentos de técnicas teatrais dentro da própria Ordem da Companhia de Jesus, por considerarem a representação muito mais eficaz aos seus propósitos (catequizar os nativos) do que os longos sermões. Para isso, usavam elementos do próprio cotidiano indígena, tais como os costumes, as máscaras, os adereços, as pinturas, etc. Eram espetáculos litúrgicos, apostolares, nos quais se juntavam anjos, 
demônios, santos, guerreiros, bichos e plantas nativas, somados a figuras alegóricas como o "Amor de Deus" e o "Temor a Deus".

Inicialmente, os autos e peças religiosas eram trazidos de Portugal, mas logo começou a surgir a dramaturgia local, pelas mãos de José de Anchieta e Fernão Cardim, por volta de 1590. Constam como de autoria de Anchieta as peças: "Auto da Pregação Universal", "Auto do Crisma”, "Auto das Onze Mil Virgens", e a obra-prima intitulada "Na festa de São Lourenço", composta por cerca de 1500 versos nas línguas tupi, guarani, espanhol e português.

Concomitantemente ao teatro catequizador, os jesuítas produziam também uma modalidade teatral paralela, em latim, com forte influência do barroco europeu, que era encenada pelos alunos dos colégios da Companhia de Jesus. Foi o marco inicial, não-oficial, do teatro estudantil brasileiro. As peças eram apresentadas nas praças, ruas, colégios e igrejas; e tal qual o resto do mundo, não admitiam a participação de mulheres.

Entendia-se por teatro estudantil, "um olhar inovador e menos convencional sobre a cena" (brazilsite/22/01/2009), muitas vezes confundido com o teatro amador, uma tendência pautada na recusa dos padrões pré-estabelecidos da expressão teatral. Oficialmente, essa modalidade teve seu início na Academia do Largo de São Francisco, por onde transitaram significativos nomes das letras e da dramaturgia nacional.

Nas pegadas do Largo de São Francisco

O Brasil ainda era Império; São Paulo ainda era Vila. No calendário: 1829. O palco: Páteo do Colégio. Lá existia o desativado Teatro São Paulo, ou Casa da Ópera local onde está hoje o Edifício da Secretaria da Fazenda (VAMPRÉ, 1977, p. 291) - que serviu de abrigo a um grupo de amigos - artistas e arteiros -, acalentando um sonho comum: fazer teatro. Um teatro como veículo de expressão de idéias e debates sobre as mazelas do País, e mais um marco histórico da Academia de Direito do Largo de São Francisco.

Sob a direção de José Joaquim de Macedo e Henrique José da Costa, a primeira peça encenada pelo grupo, genuinamente masculino, foi "Ingênua", cujo papel principal foi desempenhado por Josimo do Nascimento Silva. Nos outros papéis estrelaram Fernando Dias da Mota, Bernardo Augusto Nascentes de Azambuja e José Maria Frederico de Souza Pinto.

Entretanto, o amadorismo, entre outras tantas, sinônimo de dificuldades financeiras, como em quase todos os setores da vida humana, é golpe mortal nas pretensões culturais; e o grupo encontrou barreiras tais que o extinguiram.

Cem anos de silêncio se passaram nos palcos e só se ouvia a voz do teatro sanfranciscano traduzida em palavras, na dramaturgia e na crítica, tanto que o primeiro texto teórico que o Brasil conheceu sobre a tragédia teve a assinatura de três dos nossos 
acadêmicos: Francisco Bernardino Ribeiro, Antonio Augusto Queiroga e Justiniano José da Rocha. Diga-se de passagem, Justiniano foi o responsável pelo nascimento da crítica teatral no Brasil, em 1833. Décadas que viram despontar na Academia do Largo de São Francisco talentos como Álvares de Azevedo, com a peça "Macário e Boêmios, ato de uma comédia não escrita"; Castro Alves, que escreveu "Gonzaga ou a Revolução de Minas" e "Uma página da escola realista"; Fagundes Varela, com a "Morte do Capitão Mor"; e Paulo Eiró, Autor de "Sangue Limpo". É bem verdade terem sido estas figuras destacadas na literatura romântica e não especificamente no teatro, tratando-se tão-somente de breves insigts de talento.

Outro "filho" da Academia, entretanto, deixou marca profunda na história que contamos: José de Alencar, o introdutor da tendência realista recém-surgida na Europa (1852). Dessa nova leitura de estilo surgiram as peças “O Demônio Familiar”, “As asas de um anjo", "O Crédito", e outras.

Fugindo à regra veio França Júnior, único que se dedicava exclusivamente a escrever teatro, que enquanto aluno escreveu "Meia-hora de cinismo", "Tipos da atualidade", “A República modelo" e "Ingleses na Costa". Seguindo o exemplo de José de Alencar, França Júnior transferiu residência para a Corte, onde escreveu outras tantas. Segundo Elizabeth R. Azevedo", "França Júnior foi uma espécie de ponte entre a obra do primeiro comediógrafo nacional, Martins Pena, e o gênio do teatro,do final do século XIX, Artur Azevedo" (2007:10).

Em fins do século XIX e início do século XX, o teatro dramático perdeu força diante do surgimento do teatro musical, com suas revistas, burletas ${ }^{2}$ e operetas; registre-se aí "O Mambembe”, de José Piza e Artur Azevedo (1904).

A essa época, surgiu em São Paulo um grupo de autores de teatro de revista - a burleta sertaneja -, dentre os quais o sanfranciscano Danton Vampré, irmão de Spencer Vampré, e Autor de várias peças de revista e burleta, em parceria com o músico Marcelo Tupinambá e o também sanfranciscano Assis Pacheco.

Porém, a alegria e a descontração irreverentes do teatro de revista duraram pouco. Já na primeira década do século XX, surgiu o antídoto na retomada da comédia de costumes. Como não poderia deixar de ser, lá estava um representante do Largo de São Francisco: Abadie Faria Rosa, autor da peça "Nossa Terra", que também foi presidente da Sociedade Brasileira de Autores Teatrais e um excelente crítico.

\footnotetext{
Professora de Teatro Brasileiro e História do Teatro da Escola de Comunicação e Artes da Universidade de São Paulo/SP.

2 Comédia ligeira, originária do teatro italiano do século XVI, menos caricatural do que a farsa, e geralmente musicada (HOLANDA, Aurélio Buarque de. Novo Dicionário da Língua Portuguesa. 2. ed. Editora Nova Fronteira, 1986. p. 294).
} 
Uma figura notável: Pedro Augusto Gomes Cardim. Teve sua vida pautada no teatro, seja no âmbito político, empresarial ou profissional. Por sua iniciativa, quando vereador eleito pela cidade de São Paulo, em 1906, foi fundada a primeira escola de teatro da América Latina batizada “Conservatório Dramático e Musical de São Paulo", além da construção, em 1911, do Teatro Municipal. O ano 1916 marcou a fundação, por essa figura ímpar, da Companhia Dramática Nacional. Cardim ainda nos deixou um legado de várias peças escritas, bem ao estilo da Belle Époque européia.

A Semana de Arte Moderna, em 1922, um rasgo de rebeldia paulistana que revolucionou as artes brasileiras, deixou sua marca também no teatro. E lá estavam os acadêmicos do Largo de São Francisco: Oswald de Andrade, Guilherme de Almeida e Antônio de Alcântara Machado.

Oswald de Andrade escreveu "A Morta" e "O Rei da Vela" (1937), e o "O Homem e o Cavalo" (1943), entre outras. Além de atuar como Autor, também foi um crítico contumaz, escrevendo a coluna "Teatro e Salões", no Diário Popular, por volta de 1909. Guilherme de Almeida, bacharel na turma de 1912 e destaque também como jornalista, cronista e crítico cinematográfico, na veia literária especializou-se na poesia - influenciada pela escola neoclássica. Aventurou-se no teatro, escrevendo algumas peças em co-autoria: "Mon coeur balance" e "Leur âme”, com Oswald de Andrade, em 1916, portanto ainda na vanguarda do movimento modernista; e "O Estudante Poeta", em parceria com Jaime Barcelos, em 1939. Nesse entremeio, escreveu, em 1921, a sua "Scheherazada”, um ato em versos. Sua contribuição teatral, entretanto, foi muito mais no âmbito de traduções de peças estrangeiras. Numa outra linha, porém não menos expressiva, surge Antonio de Alcântara Machado, cronista, jornalista e crítico de teatro, cuja grande marca ficou na assinatura de uma coluna de crítica no Jornal do Comércio.

Desde os idos de 1930, o Centro Acadêmico XI de Agosto já promovia as conhecidas "Caravanas Artísticas", que percorriam os bairros da Capital, cidades do interior do Estado e até mesmo alguns países da América Latina.

Em 1948, já com uma nova roupagem, surgiu, em São Paulo, o TBC-Teatro Brasileiro de Comédia, fruto do idealismo de dois franciscanos: o GTE - Grupo de Teatro Experimental, dirigido por Alfredo Mesquita, e o GUT- Grupo Universitário de Teatro, sob o comando de Décio de Almeida Prado. Alfredo Mesquita fundou, ainda em 1948, a Escola de Arte Dramática, enquanto Almeida Prado acabou se tornando um crítico respeitado em todo o País. O Largo de São Francisco ainda nos brindou, por essa época, com o encenador e crítico de teatro Clóvis Garcia, o Autor e diretor Miroel Silveira e Eudinyr Fraga, dramaturgo e professor.

De volta ao palco o teatro das Arcadas surgiu, no Teatro Brasileiro de Comédia, Abílio Pereira de Almeida que, além de ser oriundo do GTE, foi também diretor e Autor, assinando as peças “Avenida São Luis", "8 andar”, "Santa Maria Fabril”, "Paiol 
Velho" e "Moral em concordata". Cabe, aqui, destaque para uma figura ímpar, que se tornou um dos principais atores da história do teatro no Brasil: Paulo Autran, bacharelando da turma de 1945. A ele se juntaram, no TBC, o ator Rui Affonso e o diretor Flávio Rangel. Em 1953, o grupo liderado por Gildásio Pereira encenou seu primeiro espetáculo, intitulado "Eu estive aqui", de Phiestley.

A Faculdade de Direito voltou à cena, em 1958, quando alguns de seus alunos, ligados ao Centro Acadêmico XI de Agosto, organizaram uma "Oficina” de teatro. Lá estavam: José Celso Martinez Correa, Renato Borghi, Carlos Queiros Telles e Amir Haddad; somando-se a eles a contribuição de um engenheiro da Escola Politécnica, Fauzi Arap. Ao longo dos seus quase 50 anos de existência, a Oficina produziu peças antológicas como "Pequenos Burgueses” (1963), “O Rei da Vela” (1967) e “Gracias Señor” (1971), todos sob a direção de José Celso.

A década de 60 marcou profundamente o perfil do teatro brasileiro, que entrou em uma fase de múltiplas tendências, como cita Elizabeth R. Azevedo: "o teatro político, a contracultura e a criação coletiva” (2007:10), além de admitir mulheres no elenco da dramaturgia. Renata Pallottini, Autora de "O Crime da Cabra" e "Enquanto se vai morrer"; e Hilda Hilst, de "O Verdugo" e "O rato no muro", ambas representantes das Arcadas. Outros nomes de destaque: Emílio de Biasi, Juca de Oliveira, Alcides Nogueira, Francisco Medeiros e Aimar Labaki. Em 1961, foi encenada a peça “O Quarto do Despejo".

Nos anos que se seguiram, a Academia Direito prosseguiu deixando pegadas na arte brasileira. "Pedreira das Almas", peça em dois atos de Jorge de Andrade e música de Diogo Pacheco, inaugurou o Teatro Gazeta em 18 de novembro de 1966. Em 1968, o Teatro XI de Agosto produziu a peça "Você quer fazer Vestibular?", dirigida por Paulo Altmann, na qual o Autor, o então acadêmico, e hoje funcionário, Antonio Augusto Machado de Campos Neto, transforma o exame admissional universitário em uma tragicomédia, em dois atos; e que ficou em cartaz por vários meses nos teatros Paulo Eiró, João Caetano, e Artur Azevedo. O Grupo formado por trinta alunos levava o nome de Grupo Bandeira de Teatro Amador, em homenagem à poetisa e ex-aluna Aurélia Bandeira. Entre eles: Ana Maria de Siqueira Cavalcante, Agueda Maria Lavorato Pereira, Ahida Angélica Carone, Ale Imbeloni Talge, Antonio Augusto Machado de Campos Neto, Antonio Carlos Nogueira, Cândido Pinheiro de Oliveira, Cyro Cesar Lima Rocha Ferreira, Dulcynes Areuri, Fátima Lúcia Ferraz, Giselda Maria Fernandes Novaes, Luiz Fernando Câmara Vitral, Luiz Teixeira de Carvalho, Maria Cecília Volpini, Osmar Silveira Franco, Oswaldo Luiz Pepe, Rodolfo Malanga, Suelly Fernandes, Vera Ortiz Monteiro e Vicente Rimoli Neto.

Como é próprio do amadorismo e da realidade do teatro estudantil - o caráter doméstico das produções - as montagens e os ensaios das peças eram realizados nas dependências do Centro Acadêmico XI de Agosto. A despeito das dificuldades, em 1969, estréia "Estado de Sítio", de Albert Camus, o que lhes rendeu o braço forte da 
repressão militar: foram obrigados a mudar o nome da peça para "A Peste", que ficou em cartaz no Teatro Oficina, também sob a direção de Altmann, e com cenários e figurinos de Vera Ilse Cruz.

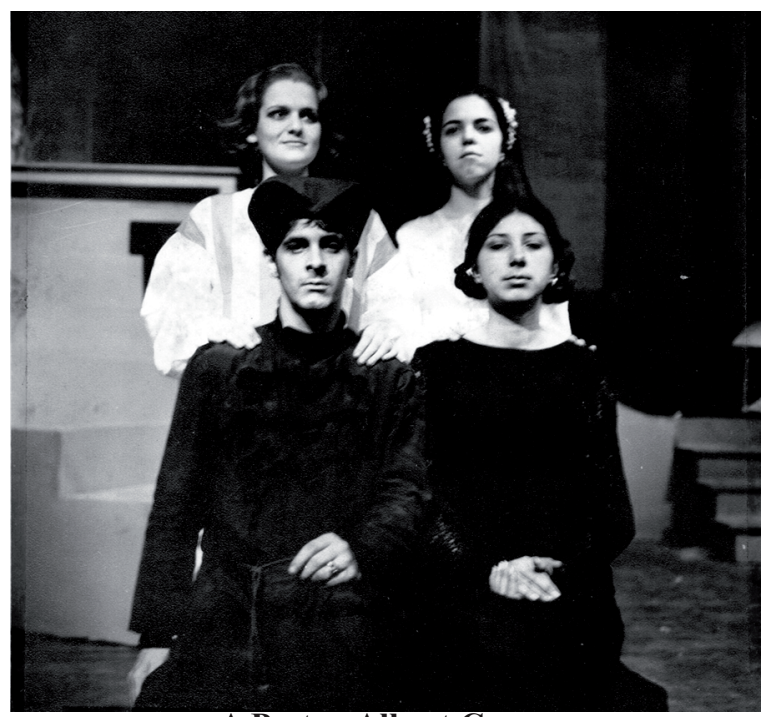

A Peste - Albert Camus

A montagem pretendia inserir o público dentro da ação, portanto, um teatro interativo. Para viabilizar uma montagem tão diferenciada para a época, o grupo ensaiava uma média de oito horas por dia, pois exigia dos atores uma excelente expressão corporal pela difícil marcação que seguia o método brechtiniano, ou seja, era praticamente coreográfica. Preliminarmente foram feitos ciclos de debates e laboratórios, inclusive com palestra do consagrado ator e diretor Plínio Marcos.

Antes mesmo da sua estréia, a peça sofreu profundos cortes de censura e teve que ser adaptada, inclusive, com mudanças radicais nas marcações. A montagem foi liberada um dia antes da sua estréia, já com o outro nome.

Idealismos exacerbados, os acadêmicos do Largo de São Francisco, em 1970, foram um pouco mais além das Arcadas. Criou-se o circo-teatro - Circo Irmãos Tibério -, erguido no Ibirapuera, com a encenação da peça "O Evangelho Segundo Zebedeu", de César Vieira (foto abaixo), desta vez com a direção de Silney Siqueira, e baseada na obra "Os Sertões", de Euclides da Cunha, o que demandou abrangente pesquisa histórica sobre a Guerra dos Canudos. 


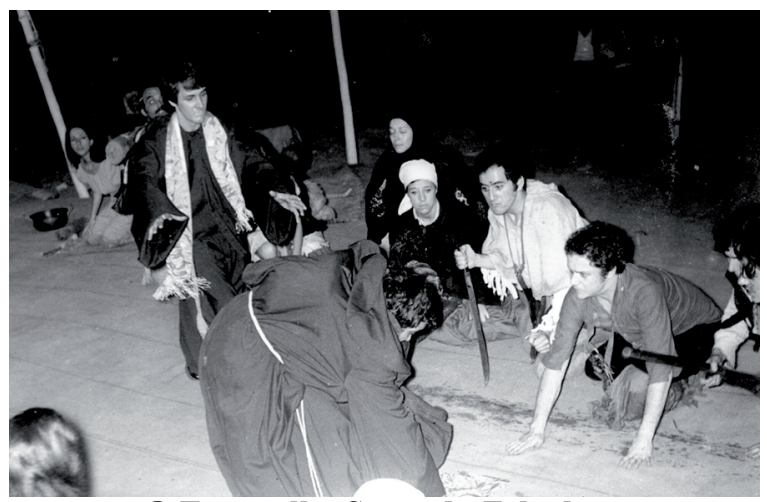

O Evangelho Segundo Zebedeu

Pode-se dizer que se tratou de um evangelho sertanejo, no qual eclode a figura mística de Antonio Conselheiro: sua vida, paixão e morte. Zebedeu é, nas palavras de seu autor, "o primeiro drama épico brasileiro, e traz em si a marca regional que se nota nas músicas e suas letras, quase todas de folclore. A linguagem em rima, usada nos dramas de circo foi mantida com toda a sua originalidade". (DN - 16/07/1970, p. 6).

Esta peça participou do Festival de Nancy, a convite da Delegação de Cultura Francesa, sendo aplaudida por participantes de vários países; e também passou pelos palcos do Festival Internacional de Teatro, em Manizales, na Colômbia. O ator, Antonio Augusto Machado de Campos Neto, participou ainda das peças "Farol da Bahia" (Autor), também encenada pelo Grupo Bandeira, e "A Bicicleta do Condenado" do espanhol Fernando Arrabal (ator).

“A Companhia Teatral Arcádia - ou simplesmente Arcádia para os íntimos - pertence a uma longa linhagem de grupos teatrais gerados nos corredores da Faculdade de Direito" (xideagosto/2006, p.1). Em toda a sua trajetória, veio driblando as intempéries, os altos-e-baixos e os hiatos, aprendendo com os erros e as defecções, e utilizando os acertos como experiência para vôos mais altos.

Esse mais recente grupo teatral da Academia do Largo de São Francisco, desde 1999, vem adaptando e apresentando várias peças de grandes autores, como Martins Pena e Fernando Pessoa, entre elas:

- “Ode Marítima” (1999): uma adaptação do poema de mesmo nome, de Fernando Pessoa;

- "O Caixeiro da Taverna" (2000 e 2004): comédia de Martins Pena;

- “ “O Açougueiro da São Francisco" (2000): espetáculo de abertura da festa de Halloween;

- "Homo Dramaticus", de Alberto Adellach;

- "Justiça", que são exercícios dramáticos e coletivos;

- "Play Becket", peça baseada na obra de Sammuel Becket;

- "A Farsa do Advogado Pathelin": farsa anônima do século XVI, traduzida por Luíz Hasselmann;

- "Photo Clown": mímicas e pantomimas de autoria de Reynaldo Puebla; 
- "Medea Material", de Heiner Müller;

- "Valsa n. 6": peça em dois atos, de Nelson Rodrigues, encenada no final de 2003;

- " “O Coração Delator": conto de Edgar Allan Poe.

Século XXI. Longe dos palcos, a Arcádia não deixou morrer a esperança e desenvolve um trabalho a partir de textos criados pelos próprios alunos, mantendo, ao mesmo tempo, um trabalho preparatório, com noções básicas de técnica vocal, expressão corporal e teatro propriamente dito. Mantém, ainda, uma Oficina de Teatro destinada a preparar o aluno-autor no domínio das técnicas de palco: prontidão corporal, liberação da imaginação teatral, montagem teatral, interpretação e criação coletiva. A título de laboratório, faz incursões relâmpago no Bandejão, nas salas de aula dos calouros, no hall dos elevadores das Arcadas, etc. A partir do $2^{\circ}$ semestre de 2005, o Arcádia saiu das oficinas para uma montagem propriamente dita, baseada em comédias de Luis Fernando Veríssimo.

Até 2005, o Grupo Arcádia esteve sob a direção de Reynaldo Puebla, que a ele se dedicava desde 1998. Com a saída de Puebla, o Arcádia adotou um novo estilo e, em 2006, produziu a peça "Vergonha Alheia", com texto de Altivo, e baseado nos autos de um inquérito policial sobre um tiro no nariz. A peça foi encenada na Faculdade de Direito como parte do Júri Simulado; espetáculo dirigido por Jamil Dias, especialmente convidado. Jamil dirigiu, também, a "Woyzeck", de Büchner. Segundo Lucas Fábio, membro da Arcádia, trata-se de "uma obra inacabada, visceral, que expressa o caos da primeira revolução industrial. E, também, foi a primeira vez que o grupo trabalhou um texto vanguardista".

Ao longo de 2007, a Arcádia foi se dissolvendo e deixou de existir em 2008, mas, como o Largo de São Francisco não se rende, nasce, em abril de 2008, o Grupo de Teatro do Largo de São Francisco. É a mais nova geração do Teatro XI de Agosto, sob a direção de Maurício Soares Filho, que nesse um ano de existência já deixou marcas com "Na Selva das Cidades", de Bertold Brecht (1 $1^{\text {a }}$ cena), e "Oficina de Teatro do Oprimido", com a participação do Grupo Metaxis-USP, o qual encabeça um projeto universitário que propõe um novo modo de interpretar o teatro, criado por Augusto Boal.

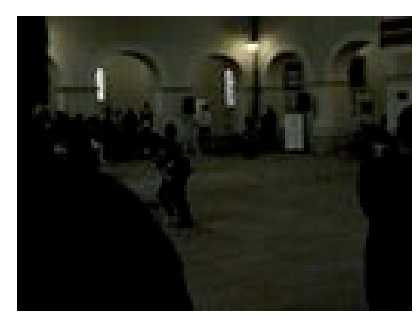

Na Selva das Cidades - Pátio das Arcadas

Para garantir o enfoque místico coerente com o clima de "Édipo Rei", próximo projeto a ser desenvolvido pelo Grupo, os atores estão recebendo aulas de yoga. 
“Edipo-Rei” terá um enfoque jurídico, já que o enredo trata de uma investigação criminal, e terá como cenário o lendário Pátio das Arcadas do Largo de São Francisco.

Para além das Arcadas

Paralelamente, no cenário nacional, o teatro estudantil fora das Arcadas do Largo de São Francisco, tomou fôlego com a fundação do Teatro do Estudante do Brasil - TEB (1938), por Paschoal Carlos Magno, na cidade do Rio de Janeiro. No ano seguinte, nasce o Teatro Acadêmico, por iniciativa de Mário Brassini, que deu origem ao Teatro Universitário - TU, em 1940, sob a direção de Jerusa Camões e com o apoio da UNE - União Nacional dos Estudantes.

Novamente por iniciativa de Paschoal, surge no Recife, em 1958, o primeiro Festival de Teatro; cidade que, desde 1946, já abrigava o Teatro do Estudante de Pernambuco (TEP), o Teatro de Amadores de Pernambuco (TAP), e o Teatro Popular do Nordeste (TPN), este último idealizado por Hermilo Borba Filho.

Em São Paulo, o Teatro Paulista do Estudante fundiu-se com o Teatro de Arena, em 1957; e a "Oficina" dá origem ao Teatro Oficina, em 1959. Com a abertura político-cultural advinda do Governo Juscelino Kubitscheck, cresceu a presença da UNE. Desse movimento ideológico-cultural nasceu o Centro Popular de Cultura UNE - o CPC, logo após as apresentações de "Eles não usam Black-tie", no Rio de Janeiro. A liderança de Oduvaldo Vianna Filho gestou um movimento cultural destinado à mobilização da população, em montagens que percorriam praças, ruas, portas de fábricas e sindicatos (Itaú Cultural, 2009-1). O teatro sempre foi a modalidade artística mais proeminente dentro do CPC-UNE.

Com a instalação da ditadura militar, em 1964, com a UNE relegada à ilegalidade, o teatro estudantil voltou ao interior das universidades: o Teatro da Universidade Católica - TUCA surgiu na PUC/SP, em 1965, encenando "Morte e Vida Severina", de João Cabral de Melo Neto. No Rio de Janeiro, também em 1965, veio à cena o Teatro Universitário Carioca - o TUCA/Rio -, dirigido por Amir Haddad, apresentando "O Coronel de Macambira”, de Joaquim Cardozo. Em 1966, surgiu, em São Paulo, o TEMA - Teatro dos Universitários do Mackenzie, com a apresentação de "A Capital Federal”, de Artur Azevedo e direção de Ruy Nogueira; e o Teatro do Sedes Sapientie - TESE, com a encenação de "As Troianas", autoria de Eurípedes e direção de Paulo Villaça.

Tantas produções transformaram São Paulo "no epicentro do movimento de teatro universitário”. Em 1967, iniciaram-se as atividades do TUSP - Teatro dos Universitários, ligado ao DCE/USP, com “A Exceção e a Regra”, de Flávio Império; e, em 1968, “Os Fuzis de Dona Tereza”, de Brecht; movimento que desapareceu com a decretação do AI-5 - a era do silêncio. Silêncio quebrado pela voz das Arcadas! 


\begin{abstract}
Em suas várias épocas, o teatro universitário representou, sempre, uma negação aos padrões artísticos vigentes - maioritariamente defendidos pelo profissionalismo -, impondo uma renovação que pretendeu atingir não apenas os meios expressivos do palco como, de modo enfático, os padrões de gosto e de consumo de atividade teatral, ampliando consideravelmente os locais de oferta. Optando por um repertório que dificilmente um conjunto profissional ousaria montar, ofereceu ao espectador um grande leque de proposições artísticas. Do Sahkespeare de 1938 chega-se ao Brecht de 1968, paulatinamente percorrendo as etapas artísticas mais significativas da arte cênica ocidental." (Itaucultural, 2009-2).
\end{abstract}

São Paulo, dezembro de 2008.

\title{
Referências
}

AZEVEDO, Elizabeth R. 180 anos de teatro, ou quase, no Largo de São Francisco. Revista Laranja Mecânica, edição comemorativa dos 180 anos, Movimento Resgate Arcadas 2007, p. 9-10, ago. 2007.

CARAVANA ARTÍSTICA, Jornal XI de Agosto, 31/03/1955, p. 4.

Companhia de Teatro da Faculdade de Direito do Largo de São Francisco. Disponível em: http:// arcadia.imescos.net/inicio.html>. Acessado em: 16 mar. 2009.

COMPANHIA Teatral Arcadia. Disponível em: <http: www.xideagosto.org.br/site2006.arcadia.php>.

HISTÓRIA DO TEATRO. Disponível em: <http://www.infoescola.com/artes/historia-do-teatro. htm>. Acesso em: 11 nov. 2008.

PEDRO, Armando. O Teatro na Faculdade de Direito. Folha Paulista, v. XIX, n. 144, p. 14, out. 1953.

Revista XI de Agosto, São Paulo, p. 9, 1966.

TEATRO DOS JESUÍTAS. Disponível em: <http://www.brazilsite.com.br/teatro/teat0a.htm>. Acesso em: 22 jan. 2009.

TEATRO GREGO. Disponível em: <http://www.suapesquisa.com/musica/cultura/teatro_grego.htm>. Acesso em: 11 nov. 2008.

TEATROUNIVERSITÁRIO. Disponívelem: $<\mathrm{http}$ //www.itaucultural.org.br/aplicexternas/enciclopedia teatro/index.cfm?fuseaction=>. Acesso em: 21 jan. 2009.

VAMPRÉ, Spencer. Memórias para a História da Academia de São Paulo. Edição comemorativa do Sesquicentenário da Instauração dos Cursos Jurídicos no Brasil (1827-1977). 2. ed. Brasília: Instituto Nacional do Livro e Conselho Federal de Cultura, 1977. v. 1. 